\title{
Alfa Natural Fiber Composite Reinforcement for Concrete Beams
}

\author{
Sofiene Helaili ${ }^{1,2, *}$, Moez Chafra ${ }^{1,3}$, Yvon Chevalier $^{4}$ \\ ${ }^{1}$ Tunisia Polytechnic School, Carthage University, LASMAP (LR03ES06), Rue El-Khawarizmi, BP 743, 2078, La Marsa, Tunisia \\ ${ }^{2}$ Carthage University, ISTEUB, Rue de l'Artisanat Charguia 2, 2035, Tunis, Tunisia \\ ${ }^{3}$ Tunis EL Manar University, IPEIEM, Campus Universitaire, B.P 244, Tunis 2092, Tunisia \\ ${ }^{4}$ Laboratoire d'Ingénierie des Systèmes Mécaniques et des Matériaux (LISMMA), SUPMECA, 93407 Saint-Ouen, France
}

Received June 5, 2021; Revised July 30, 2021; Accepted August 22, 2021

\section{Cite This Paper in the following Citation Styles}

(a): [1] Sofiene Helaili, Moez Chafra, Yvon Chevalier, "Alfa Natural Fiber Composite Reinforcement for Concrete Beams," Civil Engineering and Architecture, Vol. 9, No. 6, pp. 1677-1686, 2021. DOI: 10.13189/cea.2021.090602.

(b): Sofiene Helaili, Moez Chafra, Yvon Chevalier (2021). Alfa Natural Fiber Composite Reinforcement for Concrete Beams. Civil Engineering and Architecture, 9(6), 1677-1686. DOI: 10.13189/cea.2021.090602.

Copyright $(2021$ by authors, all rights reserved. Authors agree that this article remains permanently open access under the terms of the Creative Commons Attribution License 4.0 International License

\begin{abstract}
Lightweight, corrosion-resistant, and longer-lasting composite materials are increasingly used as primary load-bearing materials in structures' design. The cost of rehabilitating structures is lower than that of demolishing and rebuilding them again. Therefore, economical, and eco-friendly materials could extend the life of the structures and reduce the carbon di-oxide footprint on the environment. The purpose of this paper is to present a composite hollow body that can be inserted in reinforced concrete beams. The priority was to use more economical, biodegradable, and recyclable local natural fibers. The goal is to get lighter but stronger beams. The main innovation on this work is the usage of a composite made from natural fiber. A 3D finite element model of the $5 \mathrm{~m}$ span beam is developed to see in detail the beam's behavior and the composite reinforcement behavior. A classical reinforced concrete beam is compared to composite shells reinforced one. As a result, the beam is lightened, the deformation is relatively reduced, the traction in concrete is reduced, and the stress in steel bars is increased but remains far from the steel's elastic limit. An experimental work was done based on $40 \mathrm{~mm} \times 40 \mathrm{~mm}$ $\mathrm{x} 160 \mathrm{~mm}$ beams to verify the correlation of the finite element model parameters with experimental results. The results show a good correlation. The weight of the beam 5 $\mathrm{m}$ span beam is reduced by $26.65 \%$ without affecting its behavior. For the reinforced and non-reinforced $5 \mathrm{~m}$ span beams, at a similar deflexion of nearly $0.7 \mathrm{~mm}$, similar stress in concrete of about $2.3 \mathrm{MPa}$ and similar stress in
\end{abstract}

steel bars of about 10 to $13 \mathrm{MPa}$, the maximal stress in the composite is equal to $0.460 \mathrm{MPa}$ which is insignificant compared to the composite failure stress, which is about $229 \mathrm{MPa}$. The composite has a long-life and can support the efforts if the beam must be rehabilitated, for example. Consequently, lightened beams can be used in reinforced concrete structures made of non-lightened elements and have the same structural behavior.

Keywords Composites, Reinforced Concrete, Lightweight, Corrosion-Resistant

\section{Introduction}

There have been considerable interests in designing new materials for several specific applications within the past decades, such as building more resistant and lighter structures, thermal insulation, or acoustic insulation. Moreover, there has been a rising interest in using natural fibers, especially biodegradable ones; applications have spread to automotive and are becoming widely used in civil engineering, aerospace, and biomechanics as well. Examples of such materials include the Alfa plant, which is abundant in North Africa (see Figure 1), southern Europe and in Tunisia. Tunisia possesses substantial resources of Alfa plants with promising physical and mechanical characteristics. These resources can be positively exploited while preserving availability. 


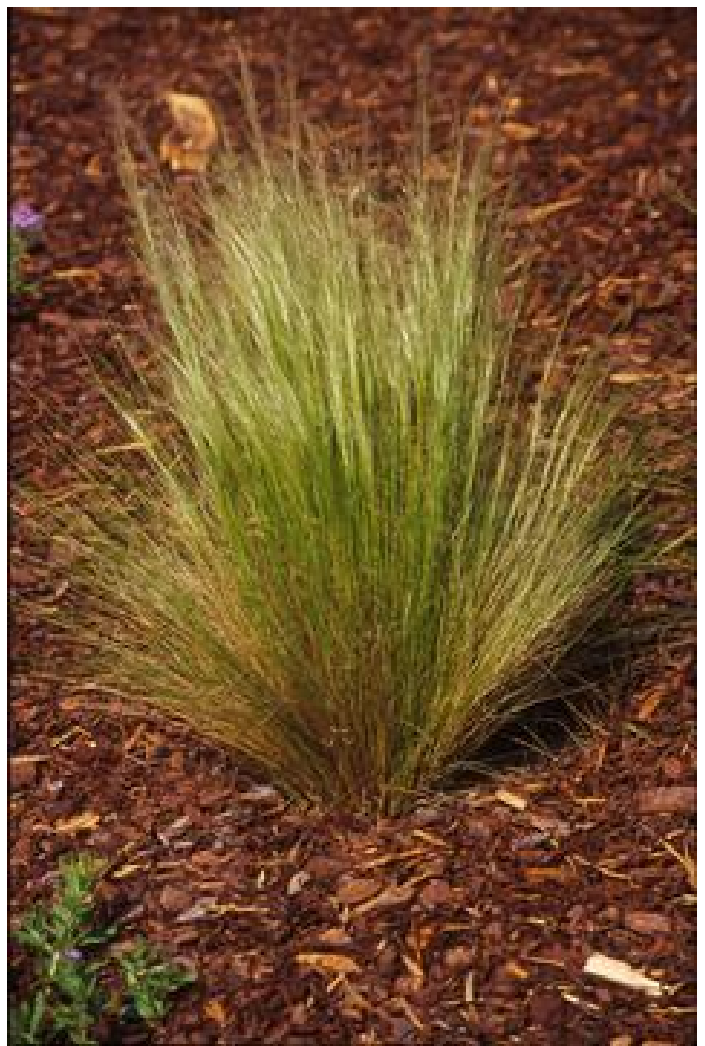

Figure 1. Alfa plant

It has been shown that these plants are chemically inert, and a priori, no dermatological or respiratory reactions are reported due to harvesting or fabrication; hence, no special protective equipment is necessary, as is the case of mineral fibers. In terms of the environment, these materials are biodegradable and recyclable.

This work's main goal is to incorporate local materials in the civil engineering and construction industry. It is planned to achieve this aim by elaborating a new composite material where the reinforcement consists of natural fibers extracted from Alfa plants.

Composites are used for aerospace [1], automotive [2], biomedical [3] applications for structural components. The usage of carbon fiber or glass fiber composites for concrete structures is mainly for rehabilitating buildings or structures [4-5]. Their use in new constructions is not yet widespread. Some countries, such as Russia [6-7] and Canada [8], adopt calculation codes for the use of synthetic fiber composites as primary frames.
Some works are done in civil engineering to compare natural fiber reinforced polymer and carbon fiber reinforced polymer in strengthening of reinforced concrete beams [9]. Optimization of reinforced concrete beams with natural fiber reinforced polymer strengthening [10] lead to a conclusion that the assessment of material cost and environmental impacts indicated that the prefabrication natural fiber reinforced polymers laminates had obvious advantages over the carbon FRP laminates. Concerning the environmental impact, some results are not so encouraging; in fact, using cradle-to-gate life cycle assessment showed that the natural fiber reinforced polymers stirrups yielded slightly lower environmental impacts than the steel stirrups. The benign environmental impacts of the flax fibers were totally nullified by the negative effects of epoxy resin [11].

Composites offer great freedom of modeling on different shapes. While metal profiles come in standard shapes, composite profiles can be extruded or mold to much more complex shapes allowing for a better volume / mechanical operation ratio. The natural fiber composites, treated in this paper, considerably reduce the costs of fabrication. The environmental impact of FRP reinforced with synthetic fibers is $66 \%$ less on the environment compared to conventional materials; composites with natural fibers reduce the environment's impact even more.

Composites are used as a coating for corrosion protection. Used in thin layers, they show superior performance in highly aggressive environments [12]. Keeping the reinforcement by steels and adding an eco-friendly, corrosion-resistant, and longer-lasting composite reinforcement having an affordable price is the project's objective in which this paper fits.

Reinforcement analyses were conducted considering the elastic-plastic behavior on elements of structures reinforced by composites [13]. A finite element modeling with particulate attention to non-linear aspects [14-15] allows the calculation of deformation, traction stresses in the concrete and steel.

\section{Methods}

The modeled beam is $5 \mathrm{~m}$ long, equally vertically reinforced, and simply supported (see Figure 1). The section $\mathrm{bx} \mathrm{h}$ is equal to $40 \mathrm{~cm} \times 50 \mathrm{~cm}$ (see Figure 2).

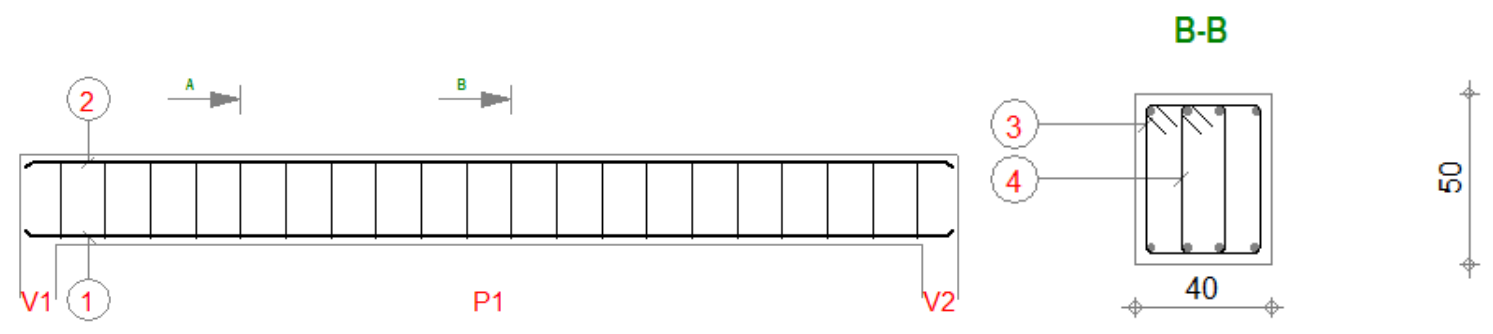

Figure 2. Reinforced concrete beam simply supported 
The beam is reinforced by four high adhesion lower tension-steel bars having $14 \mathrm{~mm}$ as diameter (index (1) in figure 2) and four upper high adhesion construction steel bars having $8 \mathrm{~mm}$ as diameter (index (2) in figure 1).

The equally spaced vertical frames are made of smooth round steel having $8 \mathrm{~mm}$ as diameter (index (3) and (4) in figure 2). The vertical frames will not be modeled in the finite element model. The coating of steel bars is $3 \mathrm{~cm}$.

\section{Materials Behavior Laws}

The model used for concrete is elastoplastic with damage. The properties of the concrete are:

- Compression resistance equal to 30.0 MPa (Concrete C30/37)

- Traction resistance equal to $2.4 \mathrm{MPa}$

- Elastic modulus equal to $34 \mathrm{GPa}$

- Poisson's ratio equal to 0.2

The stress-strain curve of the concrete is shown in Figure 3.

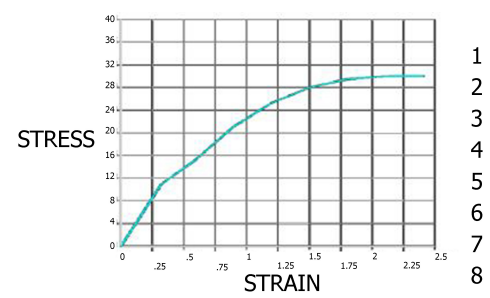

\begin{tabular}{|l|r|}
\hline STRAIN & STRESS \\
\hline 0.00032 & 10.88 \\
\hline 0.0006 & 15.28 \\
\hline 0.0009 & 21.08 \\
\hline 0.0012 & 25.27 \\
\hline 0.0015 & 27.96 \\
\hline 0.0018 & 29.42 \\
\hline 0.0021 & 29.96 \\
\hline 0.00219 & 30 \\
\hline
\end{tabular}

Figure 3. Stress-strain curve for concrete
For steel bars, the following properties are used:

- Elasticity module equal to $210 \mathrm{GPa}$

- Poisson's coefficient equal to 0.3

- Elasticity limit equal to $415 \mathrm{GPa}$

The reinforcement is achieved with hollow composite bodies composed of Alfa/PMMA 45\%. The orthotropic properties of the composite are given in Table 1.

Table 1. Mechanical Properties of the Unidirectional Composite Alfa/PMMA 45\% [16]

\begin{tabular}{|c|c|c|}
\hline E1 (GPa) & E2 $(\mathbf{G P a})$ & $\mathbf{E 3}(\mathbf{G P a})$ \\
\hline 9,718 & 4,729 & 4,729 \\
\hline $\mathrm{G} 12(\mathrm{GPa})$ & $\mathrm{G} 13(\mathrm{GPa})$ & $\mathrm{G} 23(\mathrm{GPa})$ \\
\hline 1,85 & 1,85 & 1,68 \\
\hline $\mathrm{v} 12$ & $\mathrm{v} 13$ & $\mathrm{v} 23$ \\
\hline 0,307 & 0,307 & 0,407 \\
\hline
\end{tabular}

\section{Model assumptions}

The beam is subjected to a four-point bending test. Deformation and internal efforts are presented in figure 4 . The loading points and supports are $1.6 \mathrm{~m}$ spaced. The distance between the two supports is equal to $4.8 \mathrm{~m}$. The loading force is equal to $24 \mathrm{kN}$. The resulting maximum moment is equal to $40.80 \mathrm{kN} . \mathrm{m}$. The maximal deflection is equal to $0.76 \mathrm{~mm}$.

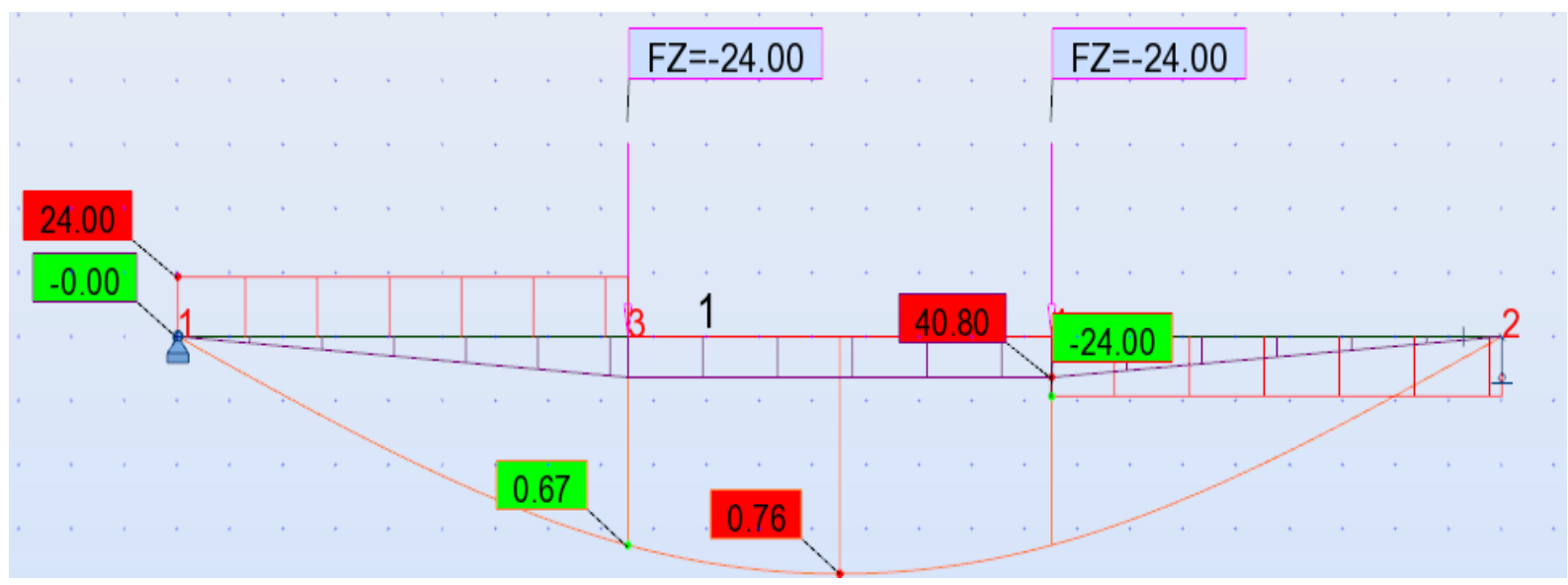

Figure 4. Beam deflection and internal efforts 
To have good modeling of shell thicknesses and geometric shapes, a 3D finite element model has been developed under the ANSYS code (see figure 5). The finite element model is non-linear and requires a converge method like the arc-length method. The problem is symmetric, so half of the model is considered.

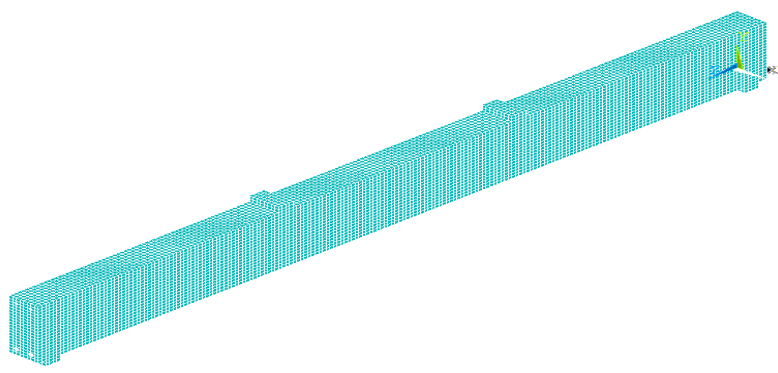

Figure 5. Half of the 3D finite element model of the rectangular beam

The concrete is made of SOLID65 finite elements. Steel bars are modeled with BEAM188 finite elements (see Figure 6).

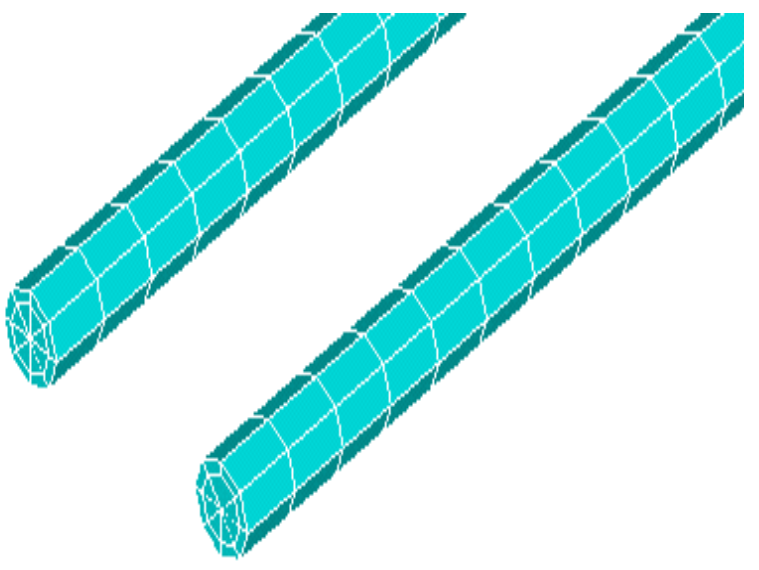

Figure 6. 1D finite element modeling of steel bars

To model the steel-concrete adhesion, the bar elements' nodes are glued to the nodes of the 3D elements. Thus, there is a continuity of deformation and transmission of efforts (see Figure 7).

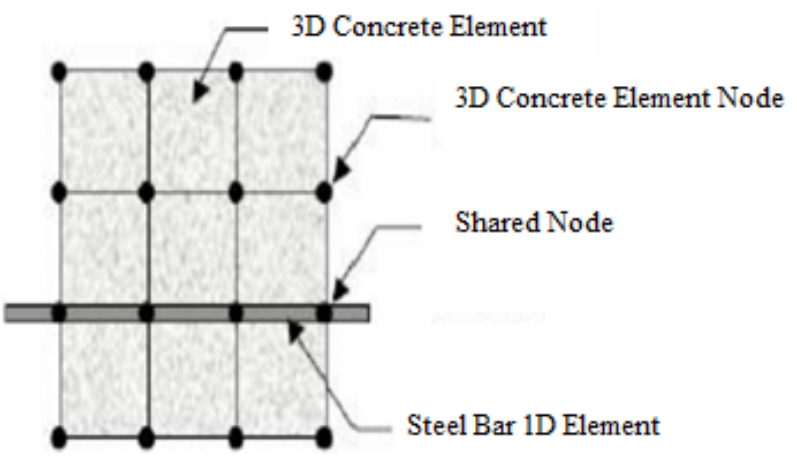

Figure 7. Nodes shared between $3 \mathrm{D}$ concrete and 1D steel elements
Composite shells are modeled with 2D SHELL181 elements (see Figure 8). Nodes of shell elements are glued to nodes of 3D finite elements to have displacement and effort continuity.

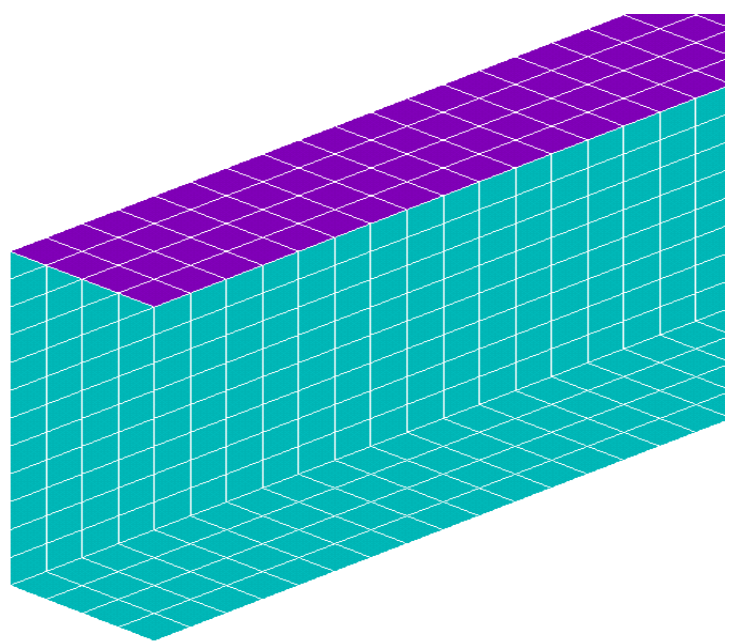

Figure 8. Half of the composite reinforcement modeled with 2D shell finite elements

\section{Experimental work}

The experimental work is conducted to check the correlation of the finite element model parameters and material parameters with the flexion experimental test. The flexion tests are conducted on a small beam $40 \mathrm{~mm}$ x 40 $\mathrm{mm} \times 160 \mathrm{~mm}$, simply supported and subject to a concentrated force in the middle of the beam. A composite plate $4 \mathrm{~mm} \times 40 \mathrm{~mm} \times 160 \mathrm{~mm}$ is glued in the bottom surface of the beam (Figure 9).

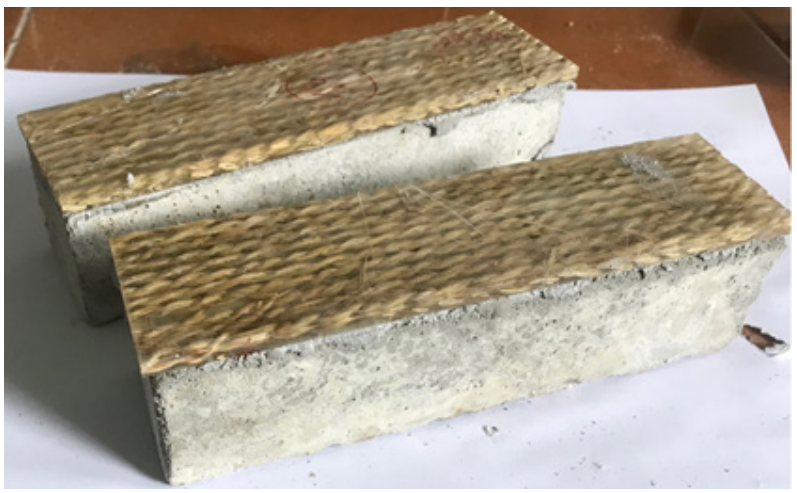

Figure 9. Stress in composite reinforcement

The unidirectional composite is fabricated using a mold (Fig. 10.a). The composite is made with a unidirectional alfa fiber (Fig. 10.b) and a resin matrix (Fig. 10.c). The composites plate (Fig. 10.d) is $4 \mathrm{~mm}$ thick and it is cut to form $40 \mathrm{~mm}$ x $160 \mathrm{~mm}$ reinforcements (Fig. 10.e). Sikadur glue (Fig. 10.f) is used to glue the composite plates to the concrete beams. 


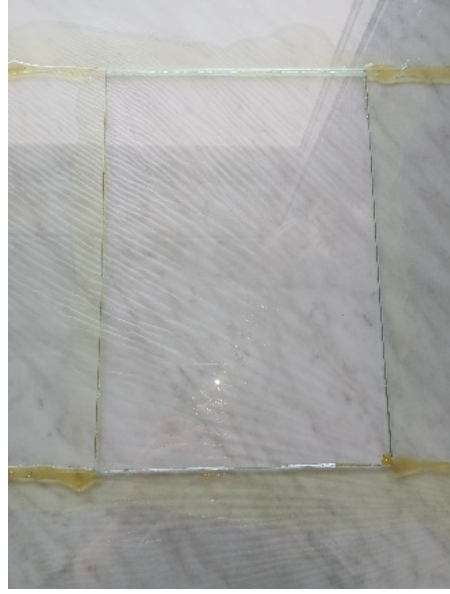

(a) Mold

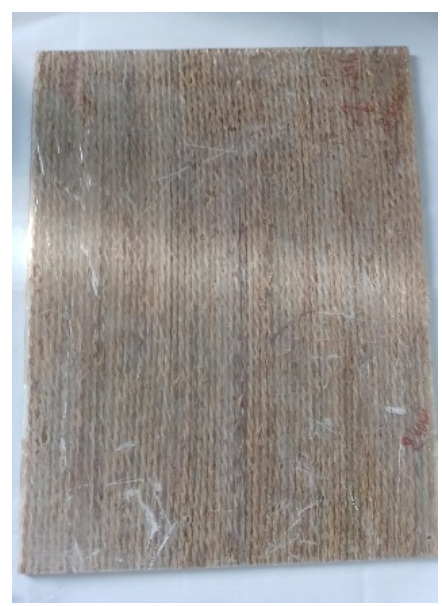

(d) Composite plate

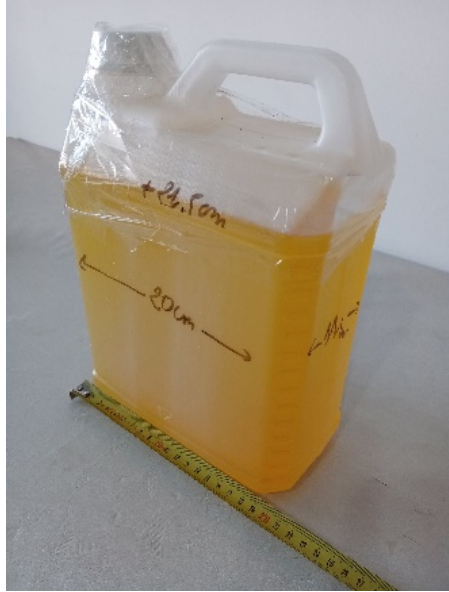

(b) Resin

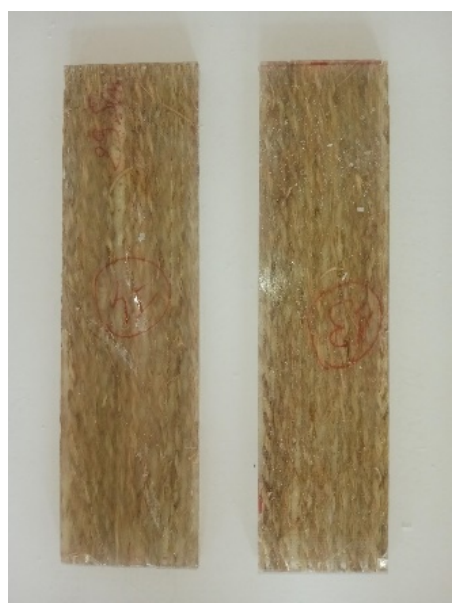

(e) Composite reinforcement $4 \mathrm{~mm}$ thick

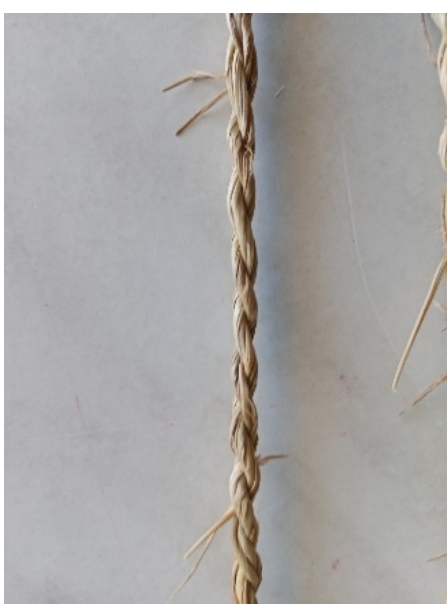

(c) Fiber

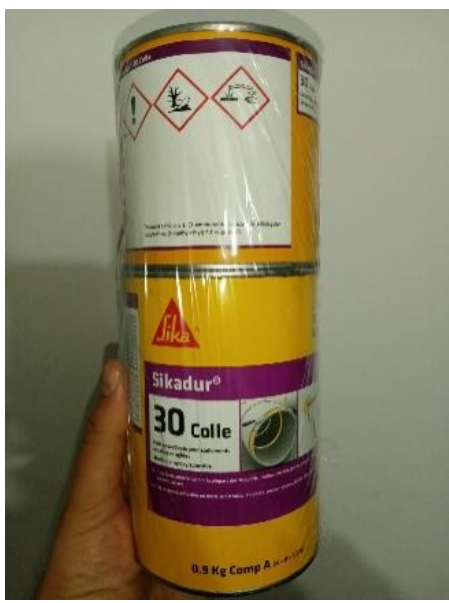

(e) Sika Composite-concrete glue

Figure 10. Composite reinforcement manufacturing

Concrete beams are made from C30/37 concrete (Fig. 11.a) using a mold (Fig. 11.b). Non reinforced concrete small beams are subjected to flexion test (Fig. 11.c) to determine the concrete flexural capacity before reinforcement.

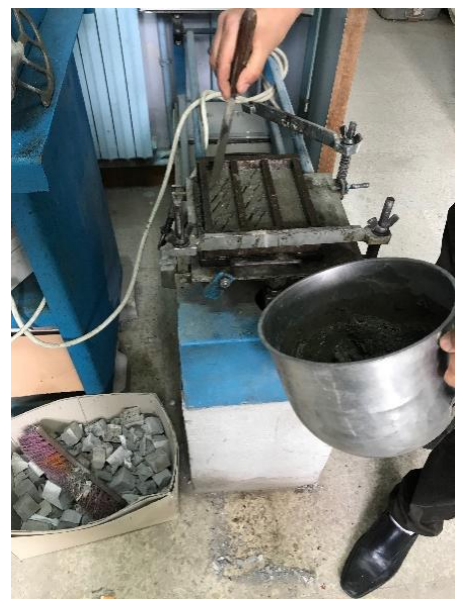

(a) Concrete mixture

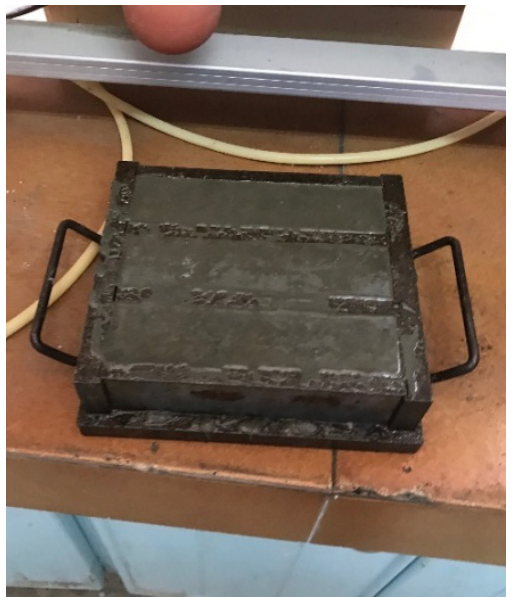

(b) Concrete mold

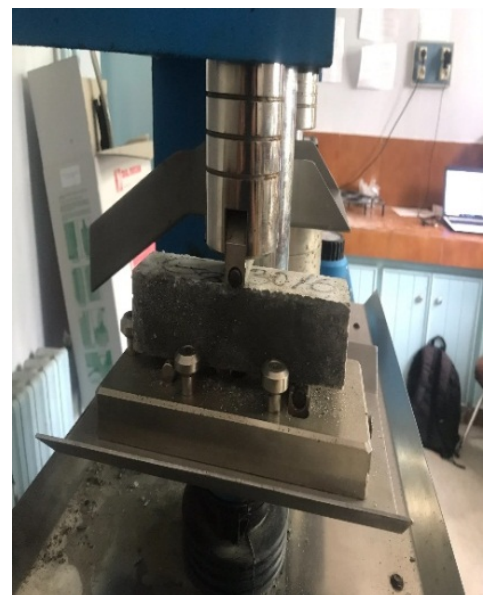

(c) flexion test machine

Figure 11. Concrete beams manufacturing and testing 

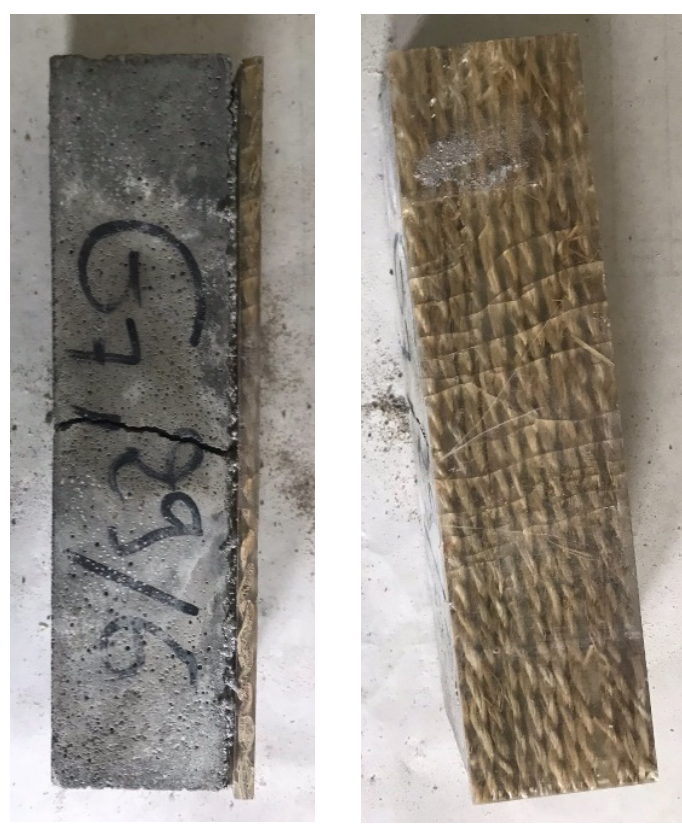

First failure mode
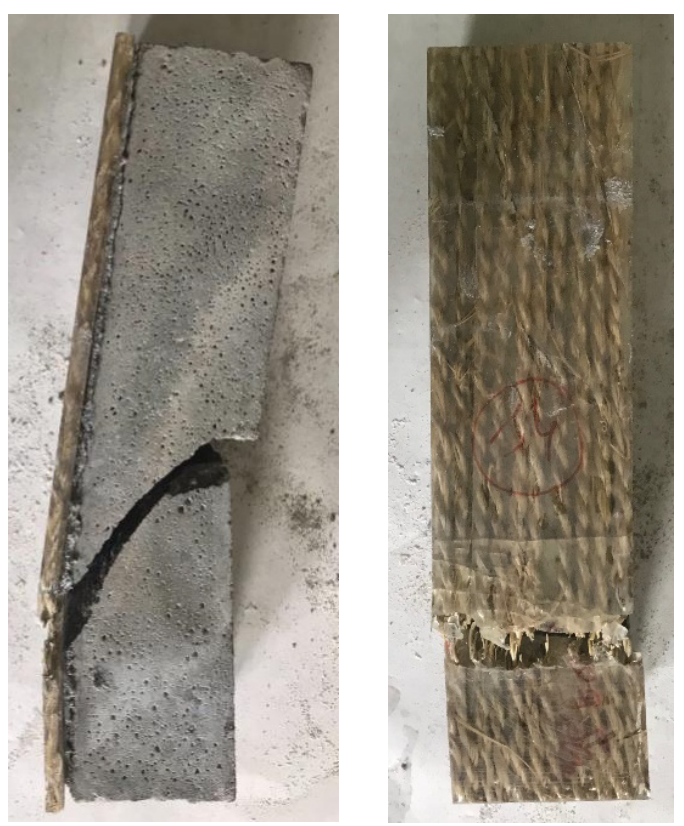

Second failure mode

Figure 12. Reinforced concrete beams failure modes

Table 2. Flexural resistance of reinforced and non-reinforced concrete beams

\begin{tabular}{|c|c|c|}
\hline & $\begin{array}{c}\text { Concrete Beam } \\
\text { non-reinf. 1 }\end{array}$ & $\begin{array}{c}\text { Concrete Beam } \\
\text { reinf. 1 }\end{array}$ \\
\hline $\begin{array}{c}\text { Flexural Stress at } \\
\text { Failure }(\mathrm{MPa})\end{array}$ & 3.82 & 23.34 \\
\hline Force at failure $(\mathrm{N})$ & 1640 & 12050 \\
\hline Ratio & 1 & 7.34 \\
\hline
\end{tabular}

Two failure modes are observed (Figure 12). The first is the concrete failure with debonding between the plate and the concrete. In the first mode, transversal cracks are observed in the reinforcing composite, but the composite do not fail. The second is the composite reinforcement failure under the support then the concrete failure due to shear stresses.

Experimental results are indicated in Table 2.

The results show that the flexural capacity of the beam increased 7.34 times.

To check the finite element models correlation, finite elements models of reinforced and non-reinforced beams are developed. The finite elements models are based on the same parameters and materials used for the $5 \mathrm{~m}$ span beam reinforced with rectangular composite hollow body.

Concrete beam maximal stress at failure, when the applied force is $1640 \mathrm{~N}$, is equal to $3.82 \mathrm{MPa}$ (Fig. 13) which is the value of stress found by the experimental work. 


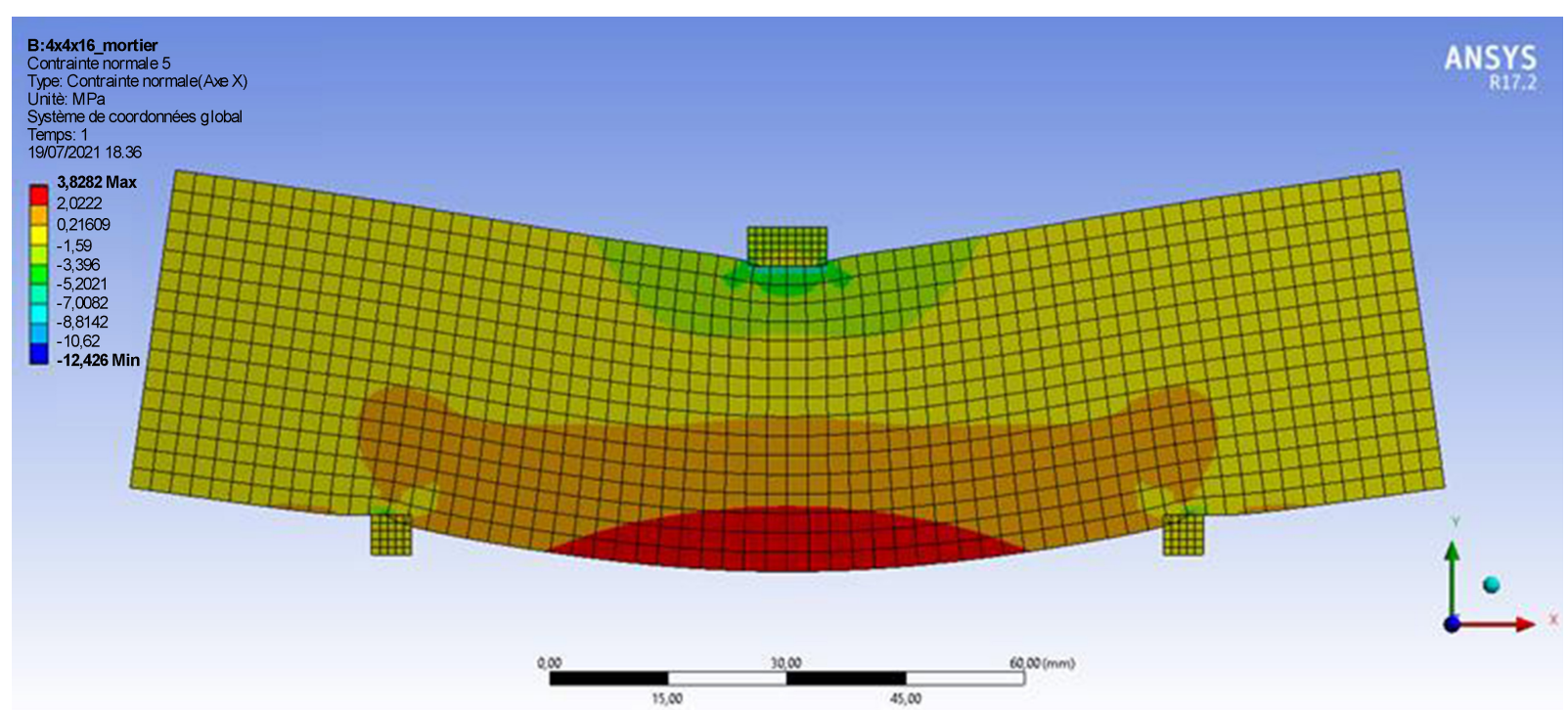

Figure 13. Concrete beam maximal stress at failure

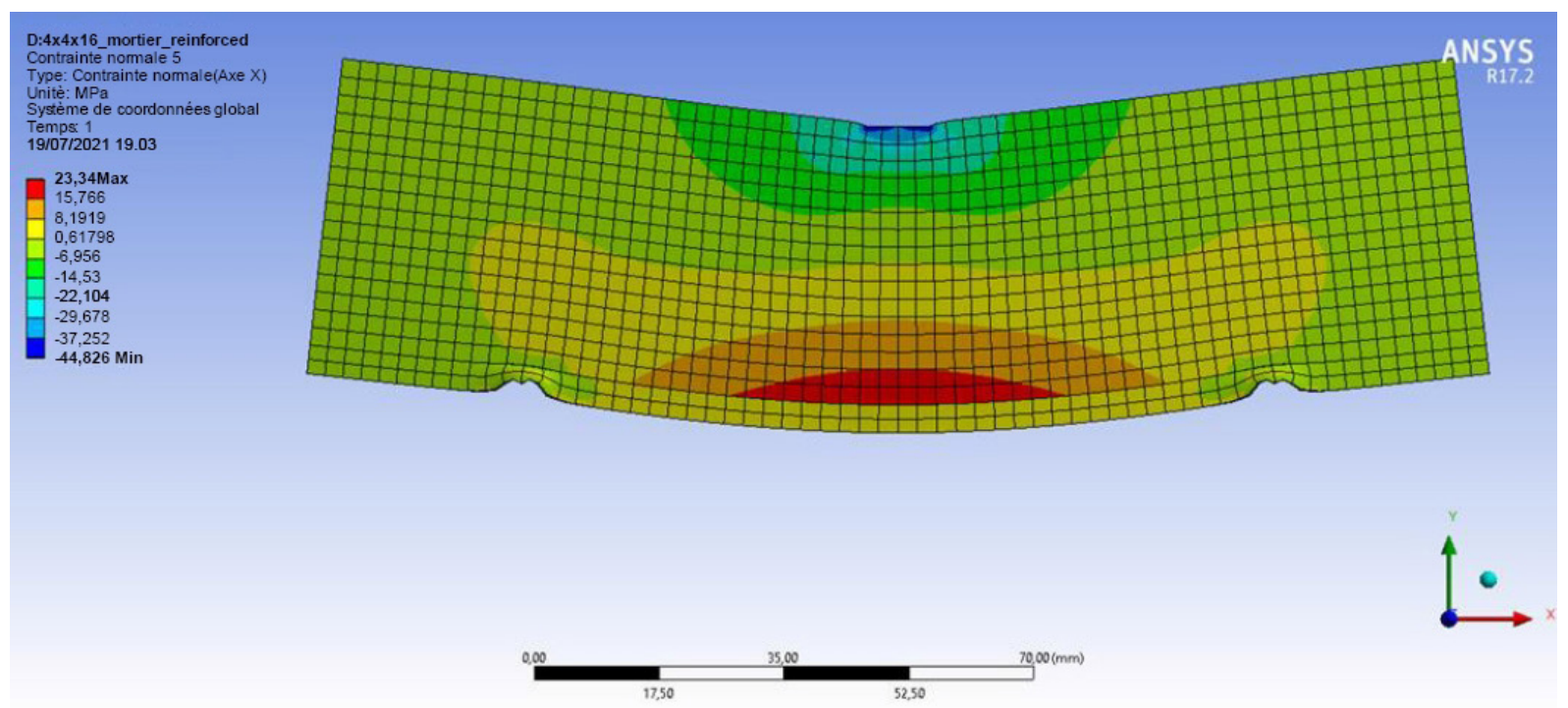

Figure 14. Reinforced concrete beams maximal stress at failure

Reinforced concrete beam maximal stress at failure, when the applied force is $12050 \mathrm{~N}$, is equal to $23.34 \mathrm{MPa}$ (Fig. 14) which is the value of stress found by the experimental work. The previous results show that the experimental work is correlated to the finite element models. As a result, the $5 \mathrm{~m}$ span beam finite elements results are validated.

\section{Results}

A first simulation modeling the rectangular $5 \mathrm{~m}$ span beam without reinforcement gives the following results:

- The deflection is equal to $0.761 \mathrm{~mm}$ (see Figure $15(\mathrm{a})$ );

- The maximum traction stress in the concrete is $2,344 \mathrm{MPa}$ (see Figure $15(\mathrm{~b})$ );

- The maximum stress in steel is $10.898 \mathrm{MPa}$ (see Figure 15(c)). 

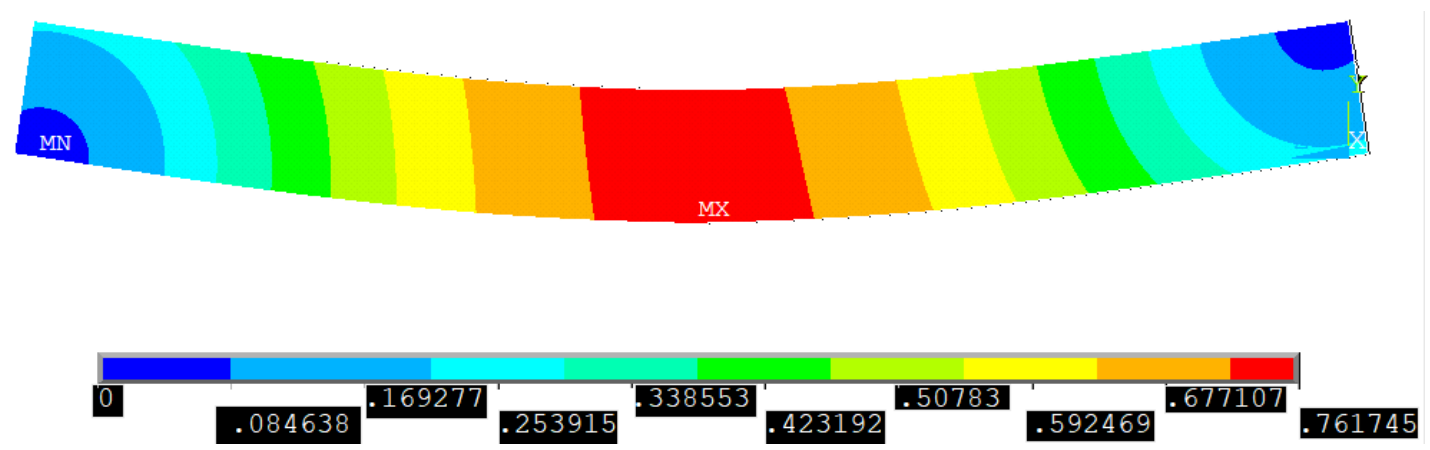

Figure 15(a). Rectangular beam deformation

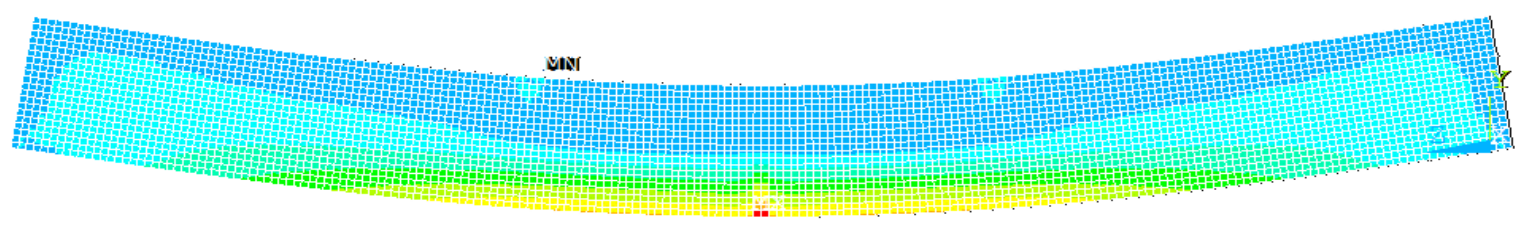

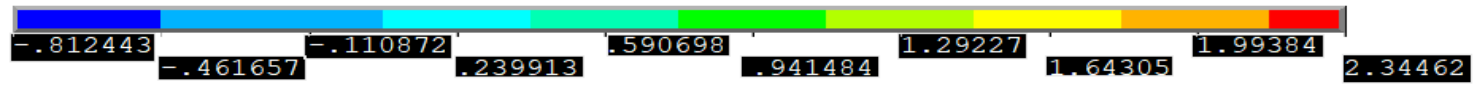

Figure 15(b). Traction stress in concrete

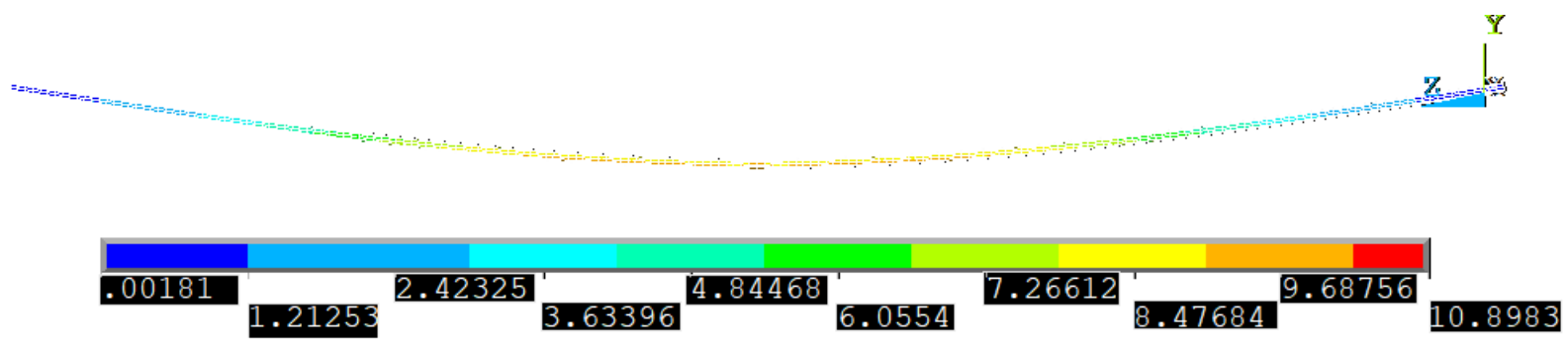

Figure 15(c). Stress in longitudinal lower steel bars

The reinforced concrete beam is lightened in the center, applying a rectangular hollow body composite reinforcement having a thickness of $1 \mathrm{~cm}$ (see Figure 16). The finite element size is $2.5 \mathrm{~cm}$. The dimension of the reinforcement is $\mathrm{h}_{\text {comp }} \times \mathrm{b}_{\text {comp }}$ equal to $30 \mathrm{~cm} \times 20 \mathrm{~cm}$. The concrete volume reduction is equal to $30 \%$. Considering the composite density equal to $1.074 \mathrm{~T} / \mathrm{m}^{3}$, the concrete density equal to $2.4 \mathrm{~T} / \mathrm{m} 3$, and the reinforced concrete density equal to 2.5 $\mathrm{T} / \mathrm{m}^{3}$ : the total weight reduction is

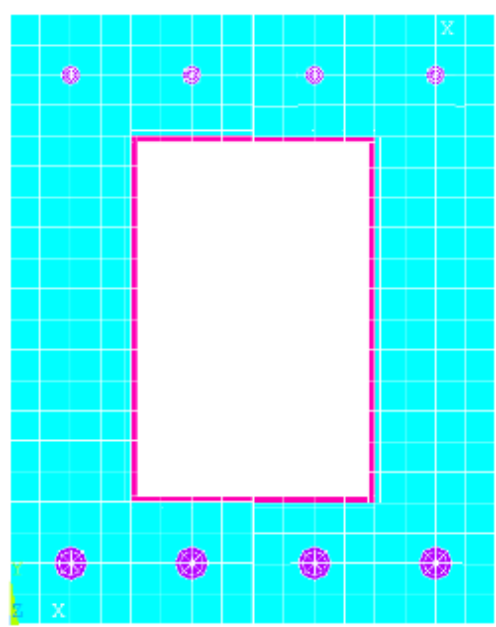

Figure 16. Rectangular section reinforced by a hollow rectangular shell in composite Alfa/PMMA 45\% 
The results are as follow:

- The deflection is equal to $0.733 \mathrm{~mm}$ (see Figure 17(a));

- The maximum traction stress in the concrete is $2.308 \mathrm{MPa}$ (see Figure 17(b);

- The maximum stress in steel is $13.104 \mathrm{MPa}$ (see Figure 17(c));

- The maximum stress in composite reinforcement is $0.460 \mathrm{MPa}$ (Figure 17(d)).
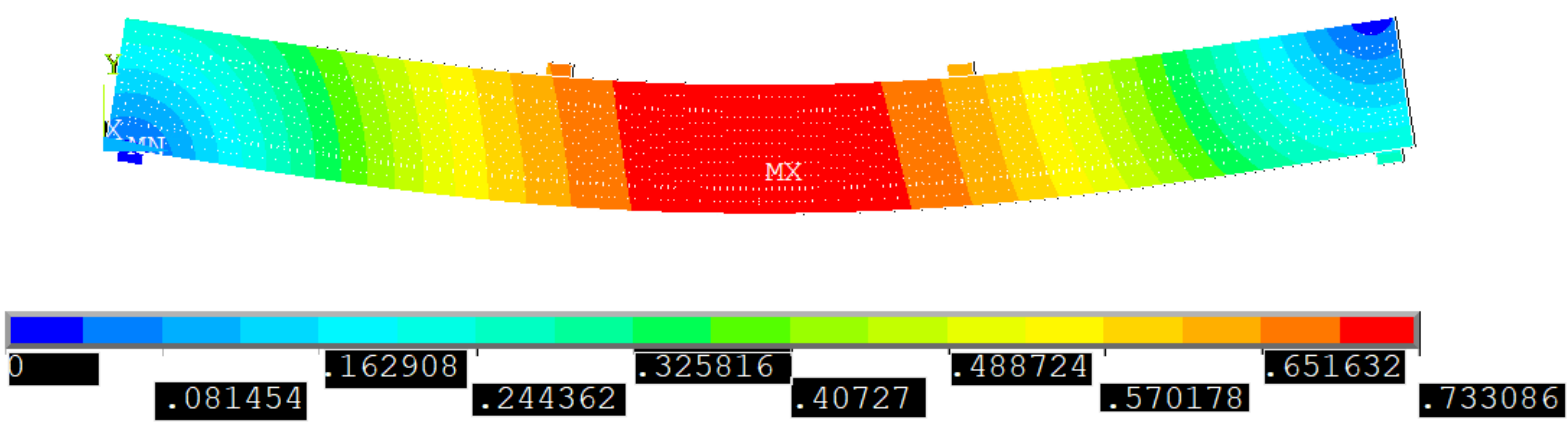

Figure 17(a). Deformation of the lightened rectangular beam
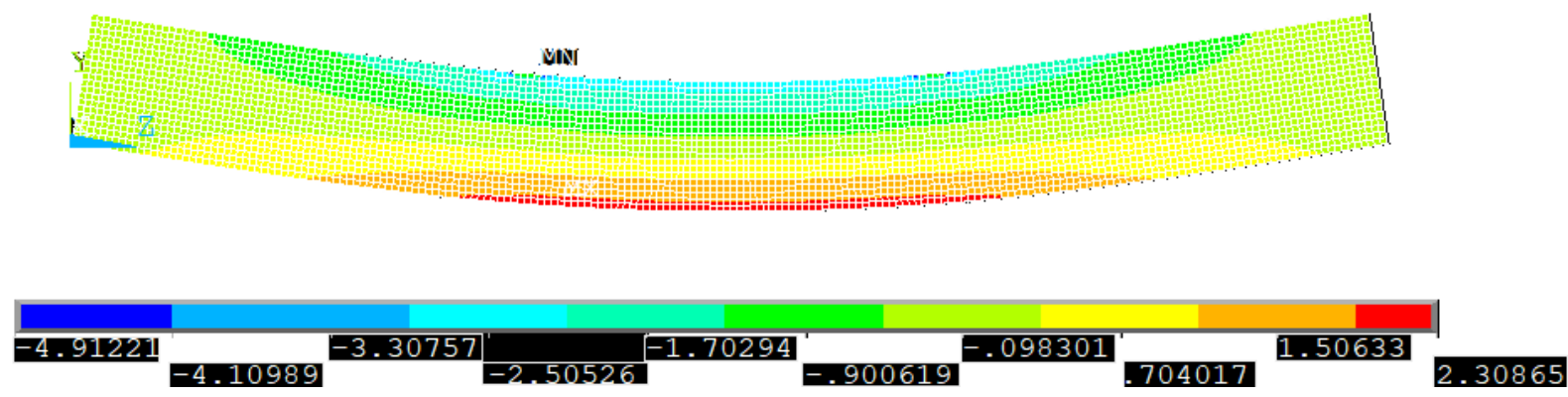

Figure 17(b). Traction stress in lightened beam concrete
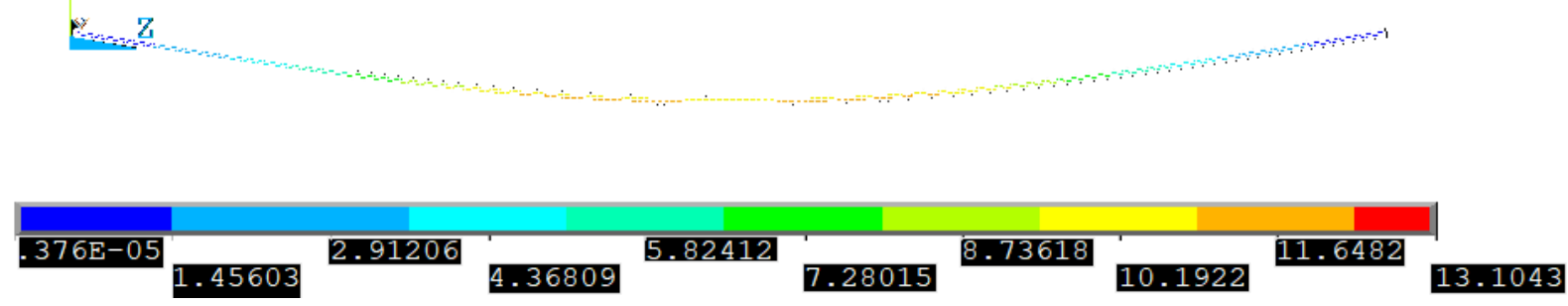

Figure 17(c). Stress in longitudinal lower steel bars in the lightened beam
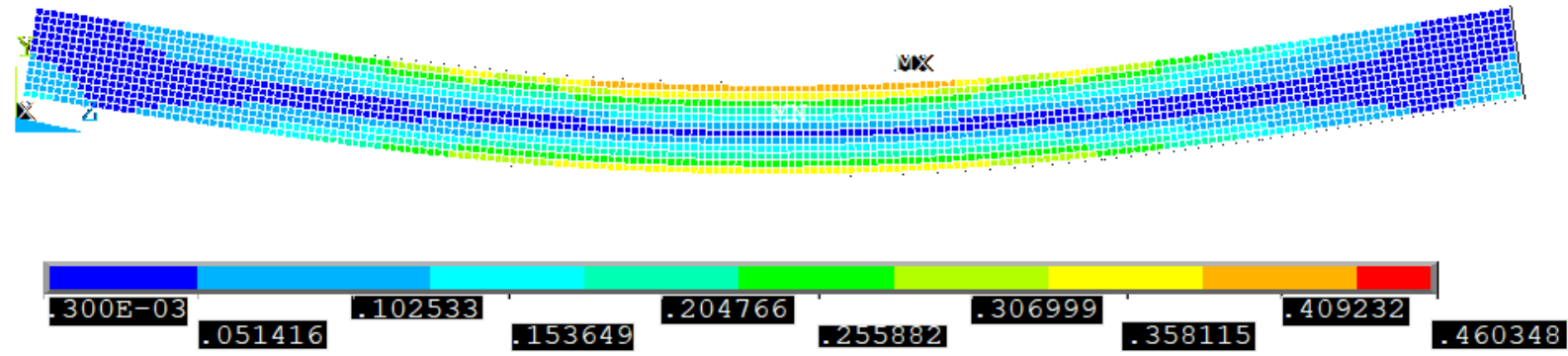

Figure 17(d). Stress in composite reinforcement 


\section{Discussion}

This first analysis presented in this paper shows that using a natural fiber composite reinforcement allows the reduction of the weight by $26.65 \%$ of the rectangular $5 \mathrm{~m}$ span beam without affecting its behavior. The maximal stress in the composite equal to $0.460 \mathrm{MPa}$ is insignificant compared to the composite failure stress, which is about 28.01 MPa [17]. The numerical and experimental results show a good correlation. In a $40 \mathrm{~mm} \times 40 \mathrm{~mm} \times 160 \mathrm{~mm}$ beam, the stress at failure is about $3.82 \mathrm{MPa}$, but if composite plates are used, the stress failure increase 7.34 times and became 23.34. The maximum applied load before failure increase from $1640 \mathrm{~N}$ to $12050 \mathrm{~N}$. As a conclusion, existing structures can be reinforced with natural alfa fiber composites.

\section{Conclusions}

New structures can be designed to be lighter with such composites and reduce the obligation to use deep foundations. The composite has a long-life and can support the efforts if the beam must be rehabilitated, for example. The usage of such composite can extend the life of the concrete by protecting it from carbonation and can protect the steel bars from corrosion. Corrosion can lead to brittle failure of buildings. Further studies are needed to optimize the shape and the thickness of the reinforcement; for example, hexagonal shapes and I-forms can be studied. The results can be compared to experimental tests.

\section{REFERENCES}

[1] Nunes JP, Silva JF. Sandwiched composites in aerospace engineering. In: Advanced Composite Materials for Aerospace Engineering [Internet]. Elsevier; 2016 [cited 2021 Jul 19]. p. 129-174. Available from: https://linkinghub.elsevier.com/retrieve/pii/B97800810003 73000055

[2] Helaili S, Chafra M, Chevalier Y. Hybrid Aluminum and Natural Fiber Composite Structure for Crash Safety Improvement. In: Karaman I, Arróyave R, Masad E, editors. Proceedings of the TMS Middle East - Mediterranean Materials Congress on Energy and Infrastructure Systems (MEMA 2015) [Internet]. Cham: Springer International Publishing; 2016 [cited 2021 Jul 19]. p. 249-258. Available from:

http://link.springer.com/10.1007/978-3-319-48766-3_25

[3] Helaili S, Mankai W, Chafra M. Pressure Calculation and Fatigue of a Trans-tibial Prosthetic Socket Made from Natural Fiber Composite. In: Feki N, Abbes MS, Taktak M, Amine Ben Souf M, Chaari F, Haddar M, editors. Advances in Acoustics and Vibration III [Internet]. Cham: Springer International Publishing; 2021 [cited 2021 Jul 19]. p. 199209. (Applied Condition Monitoring; vol. 17). Available from: https://link.springer.com/10.1007/978-3-030-76517-0_22

[4] Shamass R, Cashell KA. Experimental investigation into the flexural behaviour of basalt FRP reinforced concrete members. Engineering Structures. oct 2020;220:110950.

[5] Durgadevi S, Karthikeyan S, Lavanya N, Kavitha C. A review on retrofitting of reinforced concrete elements using FRP. Materials Today: Proceedings. avr 2020;S2214785320319283.

[6] Shamass R, Cashell KA. Experimental investigation into the flexural behaviour of basalt FRP reinforced concrete members. Engineering Structures. oct 2020;220:110950.

[7] Hamrat M, Boulekbache B, Tahenni T, Chemrouk M, Amziane S. Experimental study of deflection of steel fibre reinforced concrete beams: comparison of different design codes. European Journal of Environmental and Civil Engineering. 14 avr 2020;1-17.

[8] Raza A, Ali B, Asad Nawaz M, Ahmed I. Structural performance of FRP-RC compression members wrapped with FRP composites. Structures. oct 2020;27:1693-1709.

[9] Chen C, Yang Y, Zhou Y, Xue C, Chen X, Wu H, et al. Comparative analysis of natural fiber reinforced polymer and carbon fiber reinforced polymer in strengthening of reinforced concrete beams. Journal of Cleaner Production. 2020 Aug;263:121572.

[10] Li X, Gao Z, Zhou Y, Sui L, Chen C. Optimizing natural fiber reinforced polymer strengthening of RC beams. Mater Struct. 2021 Apr;54(2):66.

[11] Luo G, Li X, Zhou Y, Sui L, Chen C. Replacing steel stirrups with natural fiber reinforced polymer stirrups in reinforced concrete Beam: Structural and environmental performance. Construction and Building Materials. 2021 Mar;275:122172.

[12] Riaz U, Nwaoha C, Ashraf SM. Recent advances in corrosion protective composite coatings based on conducting polymers and natural resource derived polymers. Progress in Organic Coatings. avr 2014;77(4):743-756.

[13] Elchalakani M, Karrech A, Dong M, Mohamed Ali MS, Yang B. Experiments and Finite Element Analysis of GFRP Reinforced Geopolymer Concrete Rectangular Columns Subjected to Concentric and Eccentric Axial Loading. Structures. juin 2018;14:273-289.

[14] $\mathrm{Hu} \mathrm{H}-\mathrm{T}$, Lin F-M, Jan Y-Y. Non-linear finite element analysis of reinforced concrete beams strengthened by fiber-reinforced plastics. Composite Structures. févr 2004;63(3-4):271-281.

[15] $\mathrm{Hu} \mathrm{H}-\mathrm{T}$, Schnobrich WC. Non-linear finite element analysis of reinforced concrete plates and shells under monotonic loading. Computers \& Structures. janv 1991;38(5-6):637-651.

[16] Helaili S, Chafra M. Anisotropic visco-elastic properties identification of a natural biodegradable ALFA fiber composite. Journal of Composite Materials. juin 2014;48(13):1645-1658.

[17] Helaili S, Chafra M, Chevalier Y. Natural fiber alfa/epoxy randomly reinforced composite mechanical properties identification. Structures. 2021 Dec;34:542-549. 